\title{
Prescribing Pathways to Triple Therapy: A Multi- Country, Retrospective Observational Study of Adult Patients with Chronic Obstructive Pulmonary Disease
}

\author{
Jennifer K. Quint · Caroline O'Leary · Alessandra Venerus • \\ Melissa Myland · Ulf Holmgren · Precil Varghese · Hartmut Richter • \\ Geoffray Bizouard $\cdot$ Claudia Cabrera
}

Received: June 24, 2020 / Accepted: September 16, 2020 / Published online: October 16, 2020

(C) The Author(s) 2020

\begin{abstract}
Introduction: Maintenance treatment strategies in COPD recommend inhaled corticosteroid (ICS) + long-acting muscarinic antagonist (LAMA) + long-acting $\beta_{2}$-agonist (LABA) triple therapy after initial dual therapy. Little is known about how treatment pathways to triple therapy vary across countries in clinical practice.

Methods: This multi-country, retrospective cohort study (conducted 1 January 2005-1 May 2016)
\end{abstract}

J. K. Quint

Imperial College London, London, UK

C. O'Leary · A. Venerus · M. Myland

IQVIA, London, UK

U. Holmgren · C. Cabrera

BioPharmaceuticals Medical, Real World Science and Digital, AstraZeneca, Gothenburg, Sweden

\section{P. Varghese}

Biopharmaceuticals Medical, Respiratory and Immunology, AstraZeneca, Gaithersburg, MD, USA

H. Richter

IQVIA, Frankfurt, Germany

G. Bizouard

IQVIA, Paris, France

C. Cabrera $(\bowtie)$

Department of Medical Epidemiology and

Biostatistics, Karolinska Institute, Stockholm,

Sweden

e-mail: claudia.s.cabrera@astrazeneca.com included patients with a COPD diagnosis, and (UK only) evidence of smoking history, or (France, Italy, Germany, and Australia) an indicator confirming COPD diagnosis, a first instance of triple therapy recorded during the study period and $\geq 12$ months of data prior to this date. Treatment pathways to triple therapy were analyzed in patients whose first instance of triple therapy was on or after the initial COPD diagnosis. The proportion of patients who initiated triple therapy prior to initial COPD diagnosis was also estimated. Meta-analyses of the main results were performed.

Results: In 130,729 patients across all countries, mean age (standard deviation) ranged from 63.4 (10.4) years (Germany) to 69.8 (9.9) years (Italy), and median time (interquartile range) from initial COPD diagnosis to first prescription of triple therapy ranged from 16.9 (5.7-36.2) months (Australia) to 42.5 (13.9-87.4) months (UK). ICS + LABA was the most common treatment pathway prior to triple therapy in the UK, Germany, and Italy (27.3\%-31.6\%); no previous maintenance therapy prior to triple therapy was the most common pathway in France and Australia $32.5 \%$ and $37.9 \%$, respectively). Meta-analyses provided a pooled estimate of $20.4 \%$ (95\% confidence interval: $13.8 \%-29.1 \%)$ for the proportion of patients initiating triple therapy at or before initial COPD diagnosis.

Conclusions: In this retrospective cohort study, treatment pathways to triple therapy were 
diverse within and between countries. The differing impact of treatments may affect quality of life and disease control in patients with COPD. Further analyses should investigate factors influencing pathways to triple therapy.

Keywords: Adherence; Chronic obstructive pulmonary disease; Patient pathways; Realworld; Retrospective study; Stepping down; Treatment initiation; Triple therapy

\section{Key Summary Points}

In COPD, escalation to triple therapy is recommended for some patients with inadequate response to dual therapy; however, little is known about how treatment pathways vary across countries in clinical practice.

This study aimed to examine the treatment pathways to triple therapy to help inform real-world routine clinical practice across selected European countries and Australia.

The three most common maintenance treatment pathways to triple therapy were ICS + LABA, no previous therapy, and LAMA alone.

A large number of different pathways were observed both within and across countries. Future research should investigate the factors that influence pathways to triple therapy and disease outcomes related to these choices.

\section{DIGITAL FEATURES}

This article is published with digital features to facilitate understanding of the article. To view digital features for this article go to https://doi. org/10.6084/m9.figshare.12962564.

\section{INTRODUCTION}

Chronic obstructive pulmonary disease (COPD) was the third leading cause of death worldwide in 2016 [1], with an estimated global prevalence of 251 million people [2], although when considering potential undiagnosed cases, the prevalence may be much higher [3]. Diagnosis of COPD relies on clinical judgement based on a combination of medical history, symptoms, and assessment of airflow obstruction using spirometry [4]. Symptoms can include dyspnea, cough, wheeze, and sputum production, and may vary between patients [4]. COPD frequently presents with comorbidities, each of which has an impact on quality of life, hospitalization rate, and healthcare costs $[4,5]$. Asthma can also co-exist alongside COPD, which requires additional treatment $[4,6-9]$.

The severity of COPD can be quantified using the Global Initiative for Chronic Obstructive Lung Disease (GOLD) classification scheme [4]. Initially, in 2001, patients' disease severity was categorized by the degree of airflow obstruction using post-bronchodilator forced expiratory volume in 1-s spirometry results (GOLD stages 0-III) [10], which was updated in the 2006 report (GOLD 1-4) [11, 12]. In 2011, the grading system was further updated to also include symptoms and exacerbation history alongside airflow limitation severity (GOLD A-D) [13]. This study utilized the GOLD categories from the 2011 GOLD report, which was the current recommendation available during the study period.

Treatment strategies for patients with COPD include inhaled pharmacologic therapy such as short- and long-acting $\beta_{2}$-agonists (SABA and LABA), and/or short- and long-acting muscarinic antagonists (SAMA and LAMA), with or without inhaled corticosteroids (ICS) [4]. During the study period, triple therapy (ICS + LAMA + LABA) was recommended as secondline therapy for GOLD group D patients, who have a high symptom burden and exacerbation risk, in the GOLD 2011 report [13]. Likewise, triple therapy was only recommended for patients occupying GOLD group D in the GOLD 2015 report [14]. Triple therapy is currently 
recommended for patients who experience recurrent exacerbations, persistent breathlessness, or exercise limitation despite dual therapy [4]. It is more effective than dual therapies in reducing the rate of exacerbations [15-17]. Cyclic nucleotide phosphodiesterase- 4 inhibitors may also be used in patients who still experience exacerbations despite treatment with LAMA + LABA or ICS + LAMA + LABA [4].

However, little is known about how treatment patterns align with treatment guidelines across countries, with some evidence suggesting poor concordance between real-world prescribing and GOLD recommendations in singlecountry studies [18-21]. Indeed, some patients may be treated with triple therapy prior to a full formal diagnosis of COPD, or may initially be treated with triple therapy post-diagnosis $[18,19]$, which may still follow recommendations if patients were classified as severe (GOLD group D) at the time of diagnosis [14]. The decision by clinicians to step down treatment from triple to dual therapy or dual to monotherapy is challenging, due to heterogeneous populations of patients with COPD [22].

This study aimed to examine the treatment pathways to triple therapy, and time from diagnosis to initiation of triple therapy, to help inform and optimize patient treatment in realworld routine clinical practice across selected European countries and Australia. The study objectives were to: (1) quantify the proportion of patients on triple therapy prior to, at, and after initial COPD diagnosis; (2) identify pathways to triple therapy and the proportion of patients stepping down from triple therapy; (3) assess time from initial COPD diagnosis to the first prescription of triple therapy; (4) calculate adherence to triple therapy; (5) calculate the time to step-down after initiation of triple therapy.

\section{METHODS}

\section{Study Design and Patients}

A retrospective cohort study was conducted using anonymized patient electronic medical records (EMRs) from the UK, Germany, Italy, France, and Australia.

The study period was from 1 January 2005 to 1 May 2016, during which time fixed-dose combination (FDC) triple therapies were not available in any of the countries included in the study. The index date was the first instance of triple therapy during the study period. Followup ceased at transfer out of practice, end of the study period, or if death occurred.

Patients were included if they received their first triple therapy during the study period and had at least 12 months of data prior to their index date. Patients were also included if they had at least one recorded COPD diagnosis code (considered sufficient to identify COPD patients in EMRs [23]) on or after their 40th birthday and evidence of smoking (current or ex-smoker) at any point in the patient's record (in the UK) or an indicator confirming a diagnosis of COPD (all other countries). Patients with unknown gender were excluded.

For the UK, patient records were pooled from both the IQVIA Medical Research Database ([IMRD], incorporating data from The Health Improvement Network [THIN], a Cegedim database [24]), and the Clinical Practice Research Datalink (CPRD) [25] (general practitioner [GP] only), as both sources capture data from the same theoretical source population (NHS UK GP practices). Duplicate patients were removed. CPRD was linked to Hospital Episode Statistics [26] to evaluate exacerbation events reported in secondary care [27]. The patient database Disease Analyzer (DA) was used in Germany (GP and pneumologist panels) [28] and the Longitudinal Patient Data (LPD) database was used in France, Italy, and Australia, which contains anonymized patient records collected from the routine clinical management of patients via GP and other office-based specialist consultations using practice management software $[19,29]$. All databases have been validated for appropriateness regarding the representation of patient populations and sampling methods used [25, 27-30]. All data were derived from anonymized patient EMRs and reflect routine clinical care in each of the respective countries. An Independent Scientific Advisory Committee approved the use of CPRD 
data (16_298R) and a Scientific Review Committee approved the use of IMRD data (16THIN097). Approval was not required for the DA or LPD databases.

\section{Analysis}

Baseline characteristics of the study population were reported, including proportions (\%) for categorical variables and mean (standard deviation [SD]) and median (interquartile range [IQR]) for continuous variables. Comorbidities that were deemed clinically relevant to this patient population based on previous research were identified with Read codes or International Classification of Diseases codes during the 12 months prior to index [31-33]. All analyses were conducted separately for each country.

Triple therapy was defined as the simultaneous presence of ICS, LABA, and LAMA for at least 14 days, starting on the first day the three drugs overlapped, and continuing until a gap of at least 90 days was observed between prescriptions of any of the three drugs. If a gap of at least 90 days was observed between prescriptions of any of the three drugs, the drug class was assumed to have been discontinued, and therefore the patient was classified as having stepped down from triple therapy. The number (\%) of patients on triple therapy prior to, at, and after initial COPD diagnosis was reported. A meta-analysis was performed to provide a pooled estimate of the proportion of patients who initiated triple therapy prior to or at the initial COPD diagnosis.

A treatment pathway to triple therapy was created for every patient. For this analysis, prescriptions of ICS, LABA, and LAMA in the period between COPD diagnosis and triple therapy were utilized; patients whose first instance of triple therapy was before COPD diagnosis were not included and SABA and SAMA use was recorded but presented separately from the treatment pathways. Pathways were then grouped into a final list based on their frequency. After triple therapy, pathways to stepping down were determined, which included SABA and SAMA.
A meta-analysis was also performed pooling results from each country to understand the proportion of patients in the most prevalent treatment pathways, with the top three pathways per country included in the analysis. The true population prevalence of COPD was not expected to be equal in all countries due to heterogeneity in populations, treatment guidelines, and practices; as such, random-effects meta-analyses were conducted to calculate pooled estimates with $95 \%$ confidence intervals (CIs; computed using the Wald method before back-transformation using the method proposed by Freeman-Tukey) [34].

Time (months) between COPD diagnosis and initiation of triple therapy, as well as the duration of triple therapy, were analyzed. Mean (SD) and median (95\% CI, IQR) time between COPD diagnosis and index date were calculated. The median duration of triple therapy (with 95\% CI and IQR) was estimated using Kaplan-Meier survival methods (patients were censored if they were still on triple therapy at the end of their follow-up time) and reported as cumulative proportions.

To estimate adherence to triple therapy, the proportion of days covered (PDC) was calculated for each patient during the period that the patient was prescribed triple therapy (i.e., before stepping down, discontinuing [current treatment stopped] or being censored at the end of follow-up [if patients were still on treatment at the end of their follow-up time]). PDC only includes the days covered by prescriptions issued, removing any overlaps [35]. Adherence was calculated separately for the three drug classes (ICS, LAMA, and LABA) and then combined to obtain a composite adherence indicator.

\section{RESULTS}

\section{Baseline Characteristics}

The number of patients identified in EMRs was 82,300 in the UK (combined CPRD and IMRD population), 22,178 (from GP practices), and 6816 (seen by pneumologists) in Germany, 10,443 in Italy, 6514 in France, and 2478 
patients in Australia (Table 1). The mean (SD) age at COPD diagnosis was broadly similar in each country, ranging from 63.4 (10.4) years in patients seen by pneumologists in Germany to 69.8 (9.9) years in Italy (Table 1). Gender distribution varied, with Italy $(63.8 \%)$ and France $(65.0 \%)$ having the highest proportion of male patients (Table 1). Cardiovascular disease was the most prevalent comorbidity in each country but ranged from $11.5 \%$ of patients in Australia to $73.3 \%$ of GP-treated patients in Germany. The proportion of patients who had asthma (diagnosis based on relevant coding information 5 years prior to or 5 years post-COPD diagnosis) ranged from $10.4 \%$ of patients in Italy to $36.7 \%$ of pneumologist-treated patients in Germany (Table 1). The median (IQR) follow-up period ranged from 28.5 (15.0-49.1) months in Germany (pneumologists) to 49.8 (22.5-83.6) months in Italy.

\section{Treatment Pathways}

The youngest patients initiating triple therapy were found in France (mean age [SD] 65.5 [11.8] years), and the oldest were in Italy (mean age [SD] 72.5 [9.9] years) (Table 1). Patients in Australia had the shortest time from COPD diagnosis to triple therapy (median [IQR] 16.9 [5.7-36.2] months), while those in the UK experienced the longest time to triple therapy (median [IQR] 42.5 [13.9-87.4] months) (Table 2). Estimated adherence to triple therapy was generally high (> 80\% PDC), ranging from a mean (SD) $81.8 \%(15.5 \%)$ in the UK to $96.6 \%$ (6.7\%) in Australia (Table 2).

The analysis of treatment pathways suggested some cross-country trends, with the same top three pathways in each country, but there was wide variability in pathways recorded (Table 3; Fig. 1). The most commonly recorded pathway prior to triple therapy was ICS + LABA in the UK $(N=75,513 ; 27.9 \%)$, Germany (GPs $N=20,069 ; 30.2 \%$; pneumologists $N=6439$; $27.3 \%)$ and Italy $(N=8839 ; 31.6 \%)$, and no previous therapy in France $(N=5462 ; 32.5 \%)$ and Australia $(N=2136 ; 37.9 \%)$. The second most common treatment pathway to triple therapy was no previous therapy in Germany
(GPs 19.4\%; pneumologists 23.4\%) and Italy $(18.0 \%)$ and ICS + LABA in France $(28.2 \%)$ and Australia (24.1\%). LAMA alone was the second most common treatment pathway in the UK $(13.1 \%)$ and the third most common treatment pathway in all other countries, ranging from $7.2 \%$ in Italy to $22.9 \%$ in Australia. No previous therapy was the third most common treatment pathway in the UK (12.1\%). In all countries, a considerable number of pathways each included $<1 \%$ of patients per country, $(8.9 \%-26.0 \%)$ (Table 3; Fig. 1).

Although the analysis of the pathways to triple therapy focused on maintenance treatments, the proportions of patients who received short-acting bronchodilators between COPD diagnosis and triple therapy were also recorded. A large proportion of patients in each country received short-acting bronchodilators, which varied across countries: $63,473(N=75,513 ; 84.1 \%)$ patients in the UK, $10,127(N=20,069 ; 50.5 \%)$ patients treated by GPs in Germany, $3716(N=6439$; $57.7 \%)$ patients treated by pneumologists in Germany, $4000(N=8839 ; 45.3 \%)$ patients in Italy, $2124(N=5462 ; 38.9 \%)$ patients in France, and $790(N=2136 ; 37.0 \%)$ patients in Australia.

In a meta-analysis of the pathways to triple therapy, which included the proportion of patients in the top three pathways in each country (ICS + LABA, no previous therapy, and LAMA), the pooled estimate for ICS + LABA was the most common (28.3\%; 95\% CI: $26.5 \%-30.1 \%)$. The pooled estimate for the no previous therapy pathway was the second most common (22.7\%; 95\% CI 16.5\%-30.4\%), and the pooled estimate for LAMA alone was the third most common pathway overall $(11.7 \%$; 95\% CI $8.6 \%-15.7 \%)$. The proportion of patients occupying each of these pathways per country is shown in Fig. 2a-c.

Variability was also seen when examining the proportion of patients recording triple therapy on or before COPD diagnosis (Table 1): $10.8 \% \quad(95 \%$ CI $10.0 \%-11.5 \%)$ of German (pneumologist-treated) patients had triple therapy on or before diagnosis, while this was much more common in France (34.0\%; 95\% CI 32.9\%-35.2\%) and Australia (37.6\%; 95\% CI 35.7\%-39.5\%). The pooled proportion of patients who initiated triple therapy 
Table 1 Baseline characteristics for study populations across countries

\begin{tabular}{|c|c|c|c|c|c|c|}
\hline Characteristic & $\begin{array}{l}\text { UK } \\
(N=82,300)\end{array}$ & $\begin{array}{l}\text { Germany } \\
\text { (GPs, } \\
N=22,178)\end{array}$ & $\begin{array}{l}\text { Germany } \\
\text { (pneumologists, } \\
N=6816 \text { ) }\end{array}$ & $\begin{array}{l}\text { Italy } \\
(N=10,443)\end{array}$ & $\begin{array}{l}\text { France } \\
(N=6514)\end{array}$ & $\begin{array}{l}\text { Australia } \\
(N=2478)\end{array}$ \\
\hline \multicolumn{7}{|c|}{ Age at COPD diagnosis, years } \\
\hline Mean (SD) & $64.7(10.6)$ & $65.9(11.4)$ & $63.4(10.4)$ & $69.8(9.9)$ & $63.9(11.6)$ & $66.7(11.5)$ \\
\hline Median (IQR) & $\begin{array}{l}64.8 \\
\quad(57.4-72.4)\end{array}$ & $\begin{array}{l}67.0 \\
\quad(58.0-74.0)\end{array}$ & $\begin{array}{l}64.0 \\
\quad(56.0-71.0)\end{array}$ & $\begin{array}{l}71.0 \\
\quad(64.0-77.0)\end{array}$ & $\begin{array}{l}64.0 \\
\quad(55.0-73.0)\end{array}$ & $\begin{array}{l}67.0 \\
\quad(59.0-75.0)\end{array}$ \\
\hline $\begin{array}{l}\text { Gender (male), } \\
n(\%)\end{array}$ & $43,889(53.3)$ & $12,158(54.8)$ & $3773(55.4)$ & $6657(63.8)$ & $4235(65.0)$ & $1263(51.0)$ \\
\hline \multicolumn{7}{|c|}{ Comorbidities, ${ }^{\mathrm{a}} n$ (\%) } \\
\hline $\begin{array}{l}\text { Cardiovascular } \\
\text { disease }\end{array}$ & $55,076(66.9)$ & $16,267(73.3)$ & $1851(27.2)$ & $7208(69.0)$ & $3582(55.0)$ & $285(11.5)$ \\
\hline Atrial fibrillation & $6711(8.2)$ & $3311(14.9)$ & $206(3.0)$ & $990(9.5)$ & $376(5.8)$ & $37(1.5)$ \\
\hline Heart failure & $7216(8.8)$ & $5359(24.2)$ & $263(3.9)$ & $847(8.1)$ & $417(6.4)$ & $42(1.7)$ \\
\hline $\begin{array}{l}\text { Depression/ } \\
\text { anxiety }\end{array}$ & $30,810(37.4)$ & $6357(28.7)$ & $174(2.6)$ & $1168(11.2)$ & $2687(41.3)$ & $118(4.8)$ \\
\hline Osteoporosis & $6519(7.9)$ & $3294(14.9)$ & $212(3.1)$ & $1808(17.3)$ & $532(8.2)$ & $29(1.2)$ \\
\hline Diabetes & $11,978(14.6)$ & $5175(23.3)$ & $264(3.9)$ & $1176(11.3)$ & $1027(15.8)$ & $50(2.0)$ \\
\hline $\begin{array}{l}\text { Gastroesophageal } \\
\text { reflux disease }\end{array}$ & $18,846(22.9)$ & $5180(23.4)$ & $463(6.8)$ & $1903(18.2)$ & $1483(22.8)$ & $135(5.5)$ \\
\hline \multicolumn{7}{|c|}{ BMI (closest value to COPD diagnosis) } \\
\hline $\begin{array}{l}n(\%) \text { with } \mathrm{BMI} \\
\text { available }\end{array}$ & $79,564(96.7)$ & $7964(35.9)$ & $1283(18.8)$ & $7948(76.1)$ & $3974(61.0)$ & $1124(45.4)$ \\
\hline Mean (SD) & $27.1(6.3)$ & $28.5(6.5)$ & $28.2(5.9)$ & $27.9(5.3)$ & $27.0(6.0)$ & $28.2(7.1)$ \\
\hline Median (IQR) & $\begin{array}{l}26.3 \\
\quad(22.7-30.5)\end{array}$ & $\begin{array}{l}27.8 \\
\quad(24.2-31.9)\end{array}$ & $\begin{array}{l}27.5 \\
\quad(24.2-31.4)\end{array}$ & $\begin{array}{l}27.4 \\
\quad(24.4-30.7)\end{array}$ & $\begin{array}{l}26.3 \\
\quad(23.0-30.1)\end{array}$ & $\begin{array}{l}27.0 \\
\quad(23.0-32.0)\end{array}$ \\
\hline \multicolumn{7}{|c|}{ Phenotype (asthma), $n$ (\%) } \\
\hline Asthmatic & $18,800(22.8)$ & $7271(32.8)$ & $2503(36.7)$ & $1083(10.4)$ & $2364(36.3)$ & $883(35.6)$ \\
\hline Non-asthmatic & $63,500(77.2)$ & $14,907(67.2)$ & $4313(63.3)$ & $9360(89.6)$ & $4150(63.7)$ & $1595(64.4)$ \\
\hline \multicolumn{7}{|c|}{ Age at first triple therapy, years } \\
\hline Mean (SD) & $69.0(10.6)$ & $69.2(11.2)$ & $66.8(10.5)$ & $72.5(9.9)$ & $65.5(11.8)$ & $67.7(11.7)$ \\
\hline Median (IQR) & $\begin{array}{l}69.5 \\
\quad(61.8-76.8)\end{array}$ & $\begin{array}{l}70.0 \\
\quad(61.0-78.0)\end{array}$ & $\begin{array}{l}68.0 \\
\quad(59.0-75.0)\end{array}$ & $\begin{array}{l}74.0 \\
\quad(66.0-80.0)\end{array}$ & $\begin{array}{l}66.0 \\
\quad(57.0-75.0)\end{array}$ & $\begin{array}{l}68.0 \\
\quad(60.0-77.0)\end{array}$ \\
\hline \multicolumn{7}{|c|}{ Follow-up period, months } \\
\hline Mean (SD) & $46.6(33.2)$ & $39.8(30.3)$ & $35.6(27.3)$ & $55.0(37.4)$ & $47.8(33.3)$ & $44.3(31.5)$ \\
\hline
\end{tabular}


Table 1 continued

\begin{tabular}{|c|c|c|c|c|c|c|}
\hline Characteristic & $\begin{array}{l}\text { UK } \\
(N=82,300)\end{array}$ & $\begin{array}{l}\text { Germany } \\
\text { (GPs, } \\
N=22,178)\end{array}$ & $\begin{array}{l}\text { Germany } \\
\text { (pneumologists, } \\
N=6816)\end{array}$ & $\begin{array}{l}\text { Italy } \\
(N=10,443)\end{array}$ & $\begin{array}{l}\text { France } \\
(N=6514)\end{array}$ & $\begin{array}{l}\text { Australia } \\
(N=2478)\end{array}$ \\
\hline Median (IQR) & $\begin{array}{l}40.0 \\
\quad(19.3-68.4)\end{array}$ & $\begin{array}{l}32.6 \\
\quad(16.1-55.9)\end{array}$ & $\begin{array}{l}28.5 \\
\quad(15.0-49.1)\end{array}$ & $\begin{array}{l}49.8 \\
\quad(22.5-83.6)\end{array}$ & $\begin{array}{l}42.8 \\
\quad(18.2-72.5)\end{array}$ & $\begin{array}{l}38.3 \\
\quad(18.2-65.3)\end{array}$ \\
\hline \multicolumn{7}{|c|}{ Initiation of triple therapy, $n$ (\%) } \\
\hline $\begin{array}{l}\text { Before COPD } \\
\text { diagnosis }\end{array}$ & $6787(8.2)$ & $2109(9.5)$ & $377(5.5)$ & $1604(15.4)$ & $1052(16.2)$ & $342(13.8)$ \\
\hline $\begin{array}{c}\text { At COPD } \\
\text { diagnosis }\end{array}$ & $4641(5.6)$ & $1481(6.7)$ & $356(5.2)$ & $457(4.4)$ & $1164(17.9)$ & $589(23.8)$ \\
\hline $\begin{array}{l}\text { After COPD } \\
\text { diagnosis }\end{array}$ & $70,872(86.1)$ & $18,588(83.8)$ & $6083(89.2)$ & $8382(80.3)$ & $4298(66.0)$ & $1547(62.4)$ \\
\hline
\end{tabular}

$B M I$ body mass index, $C O P D$ chronic obstructive pulmonary disease, $G P$ general practitioner, $I Q R$ inter-quartile range, $S D$ standard deviation

${ }^{a}$ Proportions reflect those with non-missing values

on or before COPD diagnosis was $20.4 \%$ (95\% CI 13.8\%-29.1\%).

\section{Stepping Down}

Pathways following triple therapy included an assessment of stepping down or discontinuing treatment. The greatest proportion of patients who stepped down (84.9\%) was observed in Italy. German and Italian patients stepped down the most quickly, after a median of 2.7 months (Germany [pneumologist-treated] 95\% CI 2.6\%-2.8\%; Italy 95\% CI 2.6\%-2.9\%) of initiating triple therapy (Table 2). In contrast, $59.1 \%$ of UK patients stepped down after a median of 18.2 months (95\% CI 17.8\%-18.5\%) of initiating triple therapy. Patients in Australia tended to remain on triple therapy for more extended periods (median 5.9 months; 95\% CI 5.9\%-5.9\%) compared with patients in European countries, aside from the UK (Table 2). Except for the UK and France, the ICS + LABA regimen was the most common pathway following step down from triple therapy in all countries (ranged from $24.7 \%$ in Australia to $43.6 \%$ in pneumologist-treated German patients; Table 4).

\section{DISCUSSION}

This large, retrospective cohort study lends insights into prescribing pathways to triple therapy within clinical practice across multiple countries, indicating that patients followed a wide variety of pathways before receiving triple therapy. While recent evidence suggests benefit of triple therapy in those without a prior exacerbation history [17], GOLD recommends that patients are treated with dual therapy prior to initiation of triple therapy $[13,36]$. The addition of an ICS component to long-acting bronchodilators is recommended for prevention of exacerbations in patients with COPD. As use of ICS may increase side effects including raised risk of pneumonia, oropharyngeal candidiasis, and osteoporosis, among others, the overall risk benefit needs to be weighed in treatment decisions [4]. However, an initial prescription of triple therapy may still follow recommendations if patients were classified as severe (GOLD group D) at the time of diagnosis [14]. We found that $5.5 \%-16.2 \%$ of patients included in this analysis were prescribed triple therapy prior to a formal diagnosis of COPD and triple therapy was frequently initiated as a first-line therapy without any other prior pharmacological COPD 
Table 2 Time to triple therapy, duration of triple therapy, and adherence to triple therapy

\begin{tabular}{|c|c|c|c|c|c|c|}
\hline Variable & $\begin{array}{l}\text { UK } \\
(N=82,300)\end{array}$ & $\begin{array}{l}\text { Germany } \\
\text { (GPs, } \\
N=22,178)\end{array}$ & $\begin{array}{l}\text { Germany } \\
\text { (pneumologists, } \\
N=6816 \text { ) }\end{array}$ & $\begin{array}{l}\text { Italy } \\
(N=10,443)\end{array}$ & $\begin{array}{l}\text { France } \\
(N=6514)\end{array}$ & $\begin{array}{l}\text { Australia } \\
(N=\mathbf{2 4 7 8})\end{array}$ \\
\hline \multicolumn{7}{|c|}{ Time to triple therapy, months ${ }^{\mathrm{a}}$} \\
\hline $\begin{array}{l}n(\%) \text { with } \\
\text { data } \\
\text { available }\end{array}$ & $70,872(86.1)$ & $18,588(83.8)$ & $6083(89.2)$ & $8382(80.3)$ & $4298(66.0)$ & $1547(62.4)$ \\
\hline Mean (SD) & $60.9(63.1)$ & $48.6(47.7)$ & $46.5(38.2)$ & $46.1(37.1)$ & $36.1(32.7)$ & $26.0(27.3)$ \\
\hline $95 \% \mathrm{CI}$ & $60.4-61.3$ & $47.9-49.3$ & $45.6-47.5$ & $45.3-46.9$ & $35.1-37.1$ & $24.6-27.3$ \\
\hline $\begin{array}{c}\text { Median } \\
(\mathrm{IQR})\end{array}$ & $\begin{array}{l}42.5 \\
\quad(13.9-87.4)\end{array}$ & $\begin{array}{l}33.6 \\
\quad(14.6-66.7)\end{array}$ & $\begin{array}{l}35.4 \\
\quad(19.3-62.7)\end{array}$ & $\begin{array}{l}36.4 \\
\quad(15.8-69.3)\end{array}$ & $\begin{array}{l}26.2 \\
\quad(11.4-52.6)\end{array}$ & $\begin{array}{l}16.9 \\
(5.7-36.2)\end{array}$ \\
\hline \multicolumn{7}{|c|}{ Duration of triple therapy, months ${ }^{\mathrm{b}}$ (Kaplan-Meier estimates) } \\
\hline $\begin{array}{l}\text { Events, } \\
n(\%)\end{array}$ & $48,616(59.1)$ & $17,751(80.0)$ & $5526(81.1)$ & $8865(84.9)$ & $5137(78.9)$ & $2028(81.8)$ \\
\hline $\begin{array}{l}\text { Censored, }{ }^{\mathrm{c}} \\
n(\%)\end{array}$ & $33,684(40.9)$ & $4427(20.0)$ & $1290(18.9)$ & $1578(15.1)$ & $1377(21.1)$ & $450(18.2)$ \\
\hline $\begin{array}{l}\text { Median } \\
(95 \% \mathrm{CI})\end{array}$ & $18.2(17.8-18.5)$ & $3.6(3.5-3.7)$ & $2.7(2.6-2.8)$ & $2.7(2.6-2.9)$ & $4.7(4.4-5.0)$ & $5.9(5.9-5.9)$ \\
\hline IQR & $3.5-86.9$ & $1.4-13.5$ & $1.3-9.8$ & $1.0-11.1$ & $1.3-18.2$ & $4.2-13.9$ \\
\hline \multicolumn{7}{|c|}{ Adherence to triple therapy, measured as proportion of days covered, \% } \\
\hline Mean (SD) & $81.8(15.5)$ & $93.8(9.6)$ & $90.2(13.0)$ & $88.4(14.3)$ & $91.1(13.5)$ & $96.6(6.7)$ \\
\hline $95 \%$ CI & $81.7-81.9$ & $93.7-93.9$ & $89.9-90.5$ & $88.1-88.7$ & $90.7-91.4$ & $96.3-96.9$ \\
\hline $\begin{array}{c}\text { Median } \\
(\mathrm{IQR})\end{array}$ & $\begin{array}{l}84.4 \\
\quad(70.5-95.7)\end{array}$ & $\begin{array}{l}99.0 \\
\quad(90.8-100.0)\end{array}$ & $\begin{array}{l}98.5 \\
\quad(82.5-100.0)\end{array}$ & $\begin{array}{l}93.7 \\
\quad(81.0-100.0)\end{array}$ & $\begin{array}{l}99.2 \\
\quad(86.1-100.0)\end{array}$ & $\begin{array}{l}100.0 \\
\quad(95.7-100.0)\end{array}$ \\
\hline
\end{tabular}

$C I$ confidence interval, $C O P D$ chronic obstructive pulmonary disease, GP general practitioner, $I Q R$ inter-quartile range, $S D$ standard deviation

${ }^{a}$ Only includes patients with index date after COPD diagnosis

b Patients who stepped down or discontinued triple therapy during the study period

c Patients who remained on triple therapy until they finished the study

maintenance treatment, which could indicate that many patients were only diagnosed in the later stages of COPD when the severity required treatment with triple therapy. There is considerable variability in adherence to GOLD recommendations in general practice [37], in classification, diagnosis, and treatment plans observed between European countries [38]; however, it is perhaps unsurprising that guidelines take some time to become established in clinical practice, especially in disease areas as prevalent as COPD. Real-world data show that 1 year following the release of the GOLD 2011 guidelines, only two-thirds of patients received treatment in accordance with GOLD recommendations; instead, treatment decisions were found to be based on clinical experience [39].

Furthermore, it has been shown that, despite GOLD recommendations, spirometry is significantly under-used for the diagnosis of COPD in 


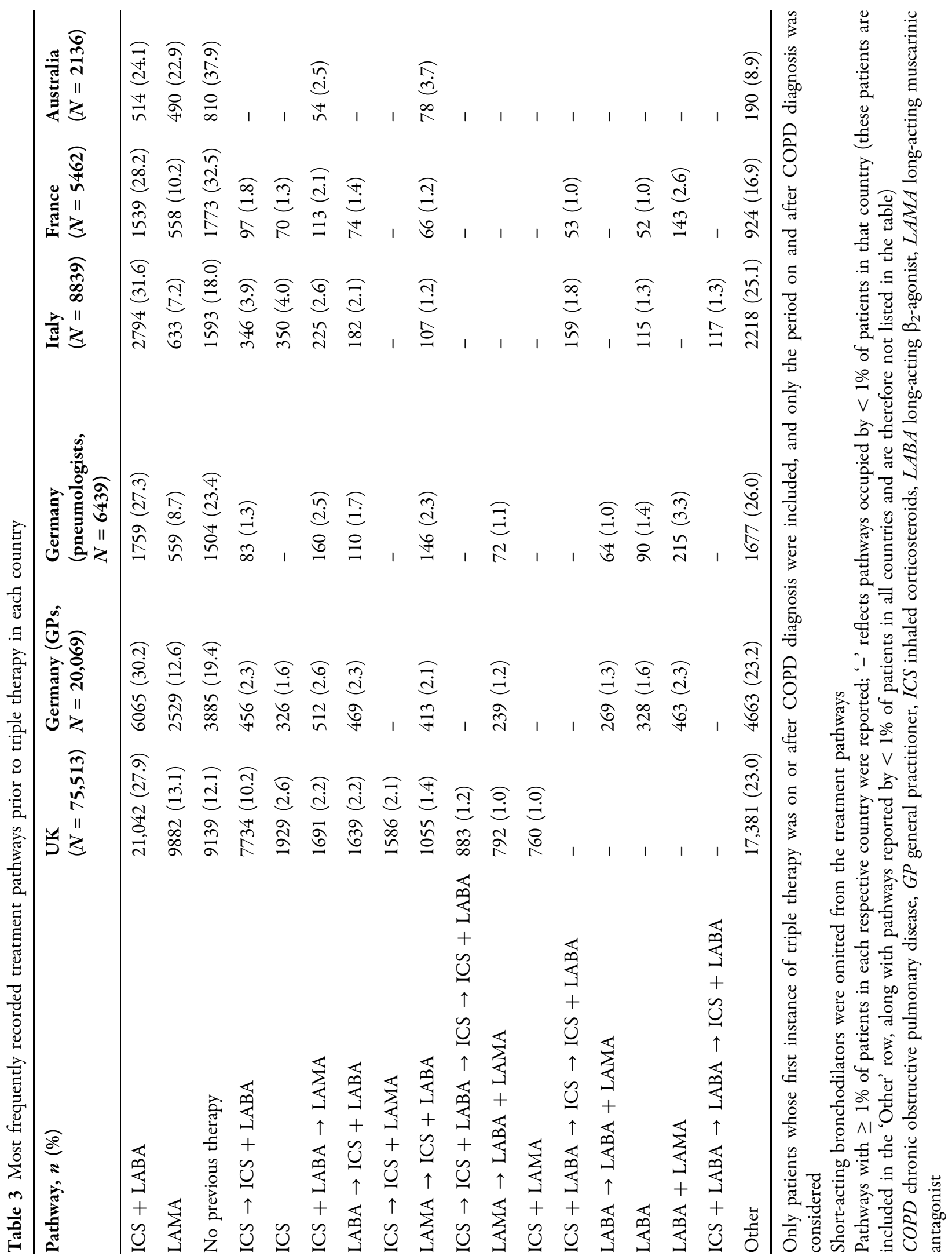


clinical practice [40]. The results of the present study can be used to further understand patient treatment pathways and may assist with the optimization of these pathways. Previously, Brusselle et al. found that of the 11,858 patients in the UK with COPD who were included, the majority of patients who received triple therapy did so within 8 years of diagnosis. Additionally, of the patients who received triple therapy, 25\% received it within 1 year of diagnosis, and over $40 \%$ received it within 2 years of diagnosis, regardless of their classification [18]. Furthermore, in an extensive study of Italian patients newly diagnosed with COPD, $6 \%$ of patients were treated with triple therapy within the first year, and $42 \%$ of these patients had no prior treatment [41].
Treatment information obtained as part of this study was based on prescriptions issued rather than those dispensed or taken by the patient. It was assumed that medications prescribed were filled and taken by the patient, with adherence estimated based on PDC. The study relied on the interpretation of prescription data to infer active decision-making on the part of the physician. Also, pathways were analyzed based on algorithms; for example, triple therapy was defined as an overlap of $\geq 14$ days in the recorded length of prescriptions and discontinuation was defined as a gap of $\geq 90$ days between refills. The absence of one maintenance treatment from prescription data was interpreted as the patient actively stepping down.

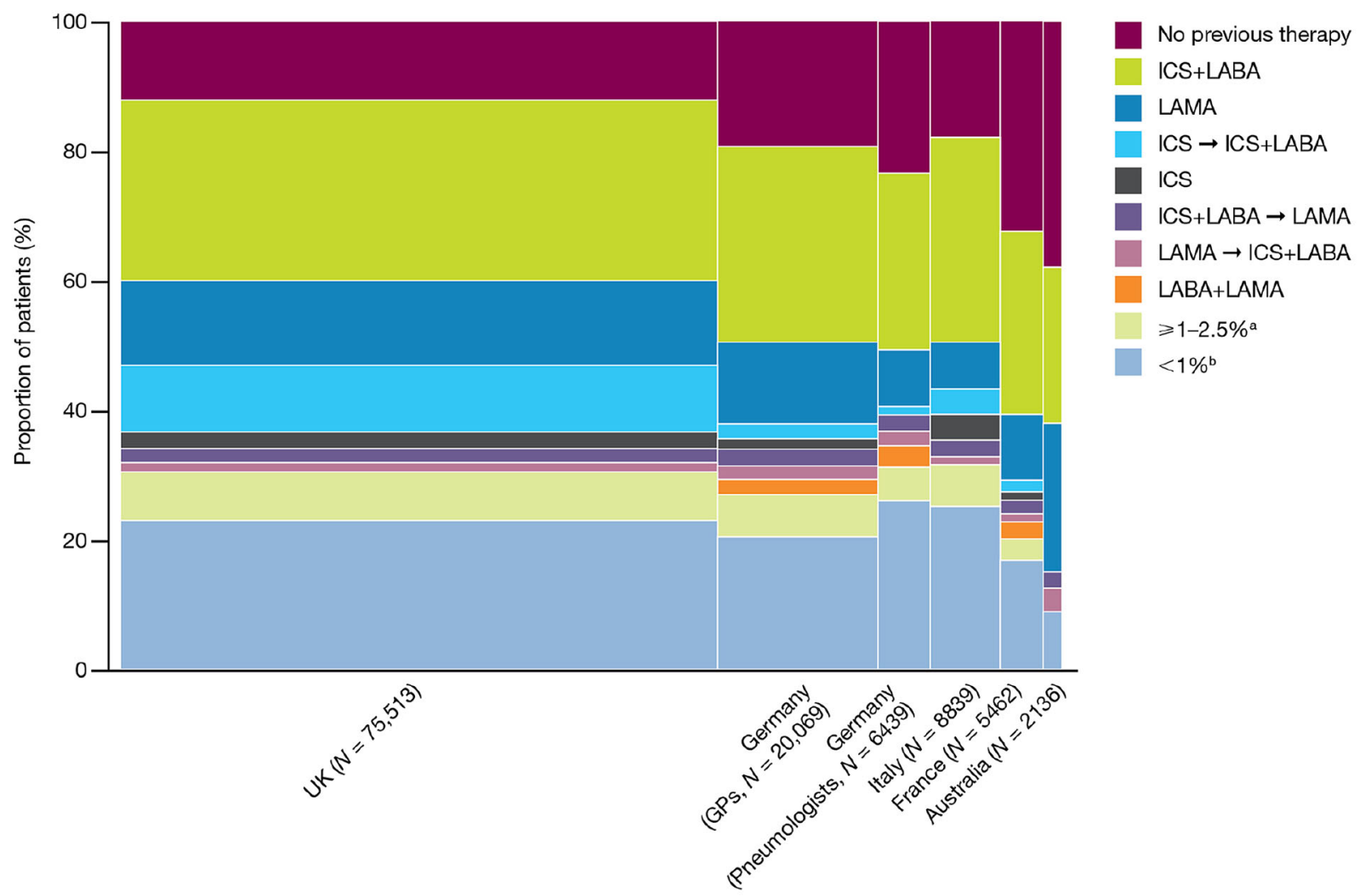

Fig. 1 Treatment pathways across countries. Only patients whose first instance of triple therapy was on or after COPD diagnosis were included, and only the period on and after COPD diagnosis was considered. Short-acting bronchodilators were omitted from the treatment pathways. Column width reflects the number of patients from each country. ${ }^{\text {a }}$ Pathways with $\geq 1 \%-2.5 \%$ of patients in each country. ${ }^{\mathrm{b}}$ Pathways with $<1 \%$ of patients in each country. GP general practitioner, ICS inhaled corticosteroids, $L A B A$ long-acting $\beta_{2}$-agonist, $L A M A$ long-acting muscarinic antagonist 
Country

UK $(\mathrm{N}=82300)$

Germany GPs (N=22178)

Germany pneumologists $(\mathrm{N}=6816)$

Italy ( $N=10443)$

France $(\mathrm{N}=6514)$

Australia ( $N=2478)$

LR test: RE vs FE Model chi^2 $=1467.6, p=0.000$ )

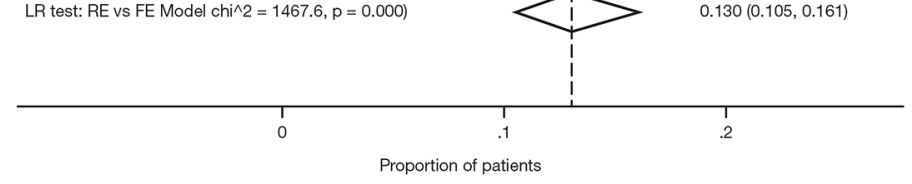

b

Country

UK ( $N=82300)$

Germany GPs (N=22178)

Germany pneumologists $(\mathrm{N}=6816)$

Italy ( $\mathrm{N}=10443)$

France $(\mathrm{N}=6514)$

Australia ( $N=2478)$

LR test: RE vs FE Model chi $\wedge 2=7732.1, p=0.000$ )

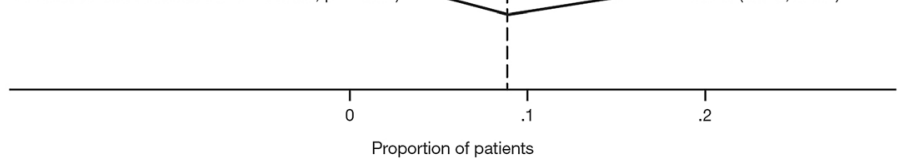

c

Country

UK $(N=82300)$

Germany GPs (N=22178)

Germany pneumologists $(\mathrm{N}=6816)$

Italy ( $\mathrm{N}=10443)$

France $(\mathrm{N}=6514)$

Australia ( $N=2478)$

LR test: RE vs FE Model chi^ $2=2543.4, p=0.000$

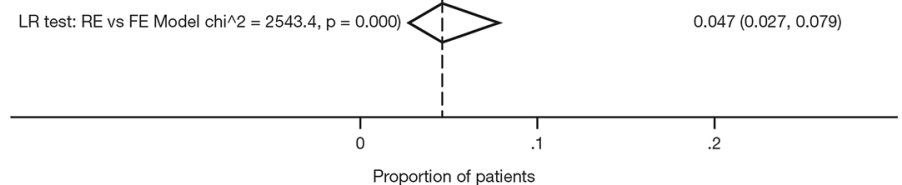

Diamonds indicate pooled estimates across countries. Values on the right represent the

proportion of patients occupying the pathway of interest in each country.

Fig. 2 Proportion of patients occupying the pathway of a no treatment, b ICS/LABA, and c LAMA only prior to triple therapy. Open/unfilled diamonds indicate pooled estimates across countries. Values on the right represent the proportion of patients occupying the pathway of interest in each country. GP general practitioner, ICS inhaled corticosteroids, $L A B A$ long-acting $\beta_{2}$-agonist, $L A M A$ long-acting muscarinic antagonist 


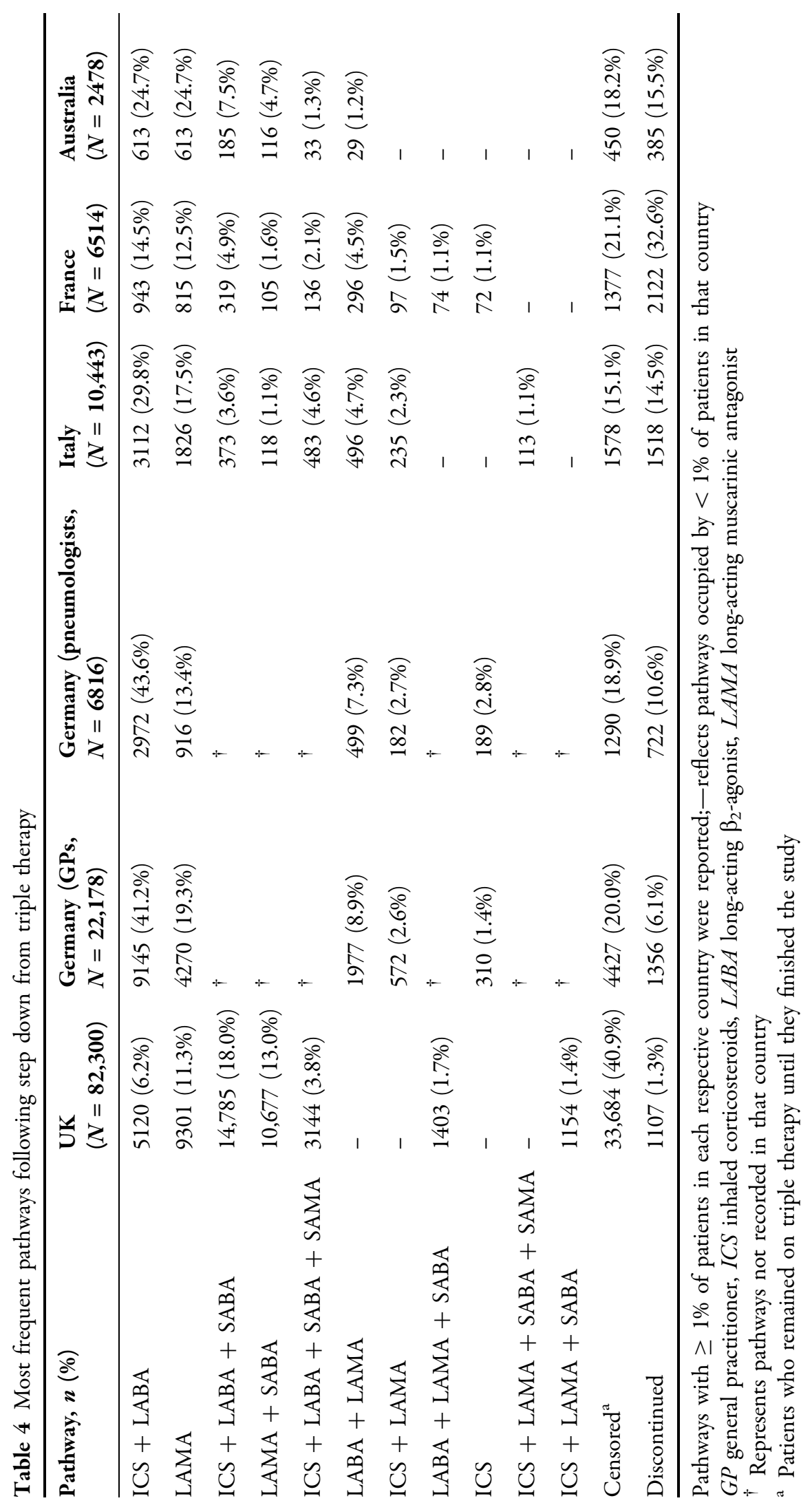


An array of pathways and timelines to initiation of triple therapy was found in our study, similar to previous estimates [18]. Specific pathways to triple therapy are likely to differ across countries due to differences in prescribing practices [38]. Similar to previous studies by Brusselle et al. in the UK [18] and Meeraus et al. in France [21], in our study, ICS + LABA was the most common treatment pathway prior to triple therapy in the UK, Germany and Italy, and the second most common pathway in France and Australia. In the meta-analysis of the treatment pathways to triple therapy, ICS + LABA alone was the most common treatment pathway prior to triple therapy in $28.3 \%$ of patients overall. However, several other pathways that included earlier treatments also ended in ICS + LABA as the last treatment prior to triple therapy, meaning that the proportion of patients receiving triple therapy as a step-up from ICS + LABA was higher. No previous therapy was the second most common pathway $(22.7 \%)$, and LAMA only was the third most common pathway (11.7\%). Another UK study demonstrated that the patients most likely to initiate triple therapy were those who were initially treated with LAMA [20].

In the multi-country study reported here, triple therapy was initiated within a mean of 2 to 5 years from COPD diagnosis, and the duration of triple therapy tended to range from a median of 3 to 18 months across countries, despite similar follow-up periods (median range 29-50 months). Observational research has not typically examined the duration of triple therapy.

The use of triple therapy may be influenced by the coexistence of asthma with COPD, with treatment strategies often aimed at asthma management [9]. Distinguishing chronic asthma from COPD using current techniques is difficult, and asthma-COPD overlap may be assumed [9]. Asthma-COPD overlap often has worse outcomes than either disease alone, and treatment solely with bronchodilators is usually avoided, due to the associated risks of this treatment approach [9]. In these cases, ICS + LABA is recommended, which could increase the use of ICS-containing regimens [9]. However, in the present study, stratification of the data into subgroups with and without asthma showed that approximately two-thirds or more of COPD phenotypes were primarily non-asthmatic across countries. Although difficult to codiagnose, $15 \%-20 \%$ of COPD patients may have asthma $[9,42]$. The higher prevalence of asthma in several countries (Germany, France, and Australia) may have resulted from previously misdiagnosing COPD as asthma [23]. It should be noted that the previous studies that evaluated pathways to triple therapy, by Brusselle et al. and Wurst et al. in the UK and Meeraus et al. in France, excluded patients with a diagnosis of asthma [18, 20, 21].

Blood eosinophil (EOS) counts could potentially guide more efficient prescription of ICS in patients with moderate-to-very severe COPD, given the increased benefit of ICS observed in patients with higher EOS counts $\left(\geq 100\right.$ cells $/ \mathrm{mm}^{3}$ ) compared with lower EOS counts $\left(<100\right.$ cells $\left./ \mathrm{mm}^{3}\right)$ [4]. Additionally, GOLD guidelines suggest blood EOS count could be used alongside other clinical assessments (such as prior exacerbation history) to guide future ICS prescription due to the known relationship between blood EOS count and observed treatment benefits [4]. Current ERS guidelines recommend maintaining ICS use in patients with EOS counts $\geq 300$ cells/ $\mathrm{mm}^{3}$ and withdrawal for patients with EOS counts $<300$ cells $/ \mathrm{mm}^{3}$ having $<2$ exacerbations per year and no hospitalization events [43].

After stepping down or discontinuing from triple therapy, most patients recorded ICS + LABA or LAMA only, which corresponds with the findings by Meeraus et al. in France [21]. The availability and actual use of LAMA/LABA FDCs was very low during the study period, which may impact prescription choices and the decision to recommend that a patient steps down in their medication regimen. A previous study of two cohorts of French patients showed lower rates of discontinuation in patients who received triple therapy versus those who received long-acting bronchodilators only, and that guidelines were not always followed [21]. Withdrawal of the ICS component can be considered in the case of adverse effects (such as pneumonia), a reported lack of efficacy [4], or in patients without an established frequent 
exacerbation history [43]. However, as blood eosinophil counts increase $\geq 150$ cells $/ \mathrm{mm}^{3}$, rates of exacerbations after ICS withdrawal increase [44]. Therefore, if removing ICS, patients should be followed closely to monitor relapse of exacerbations [4].

A unique strength of this study is that it provides a holistic view of pathways to triple therapy using large populations for analysis derived from COPD care settings across multiple countries. Due to common misdiagnosis, a validated algorithm was also used to classify patients with COPD in each database [23]; therefore, results are likely to apply to the general population of patients with COPD.

Some limitations should be acknowledged when interpreting the findings of the study. Owing to differences in data across countries, criteria for defining the initial cohort were adapted as needed; accordingly, populations may not be directly comparable. However, this was taken into account by the methods used to conduct the meta-analysis [34]. Additionally, attributing GOLD categories was not possible for a large number of patients, and variation in the incidence and types of comorbidities between countries may be due to differences in recording practices across countries. It should be noted that individual countries' prescribing practices will be impacted by drug availability/ accessibility, reimbursement, and cost, which may have influenced the pathways reflected within the results of this study. Moreover, as previously reported [45], GOLD guidelines are updated on an annual basis to ensure current recommendations are based on the most recently available, published evidence. National and regional guidelines may not be updated as frequently, may be based on the constraints outlined above, and thus may differ as a result. All national guidance documents for countries included within the analysis of this study considered triple therapy for patients experiencing exacerbations despite dual therapy, but differed in whether the step-up pathway should be from LAMA/LABA or ICS/LABA. For example, German and Australian guidelines recommend triple therapy for patients with forced expiratory volume in $1 \mathrm{~s}\left(\mathrm{FEV}_{1}\right)<50 \%$ and $\geq 2$ exacerbations per year, but in France and the UK, triple therapy was recommended for patients experiencing persistent exacerbations on dual therapy or ICS/LABA, respectively. Italian guidelines recommend triple therapy for patients with $\mathrm{FEV}_{1}<60 \%$ predicted, having $\geq 2$ exacerbations per year and persistent symptoms despite ICS/LABA therapy [45]. Furthermore, since ICS/ LAMA/LABA FDCs were not available during the study period and LAMA/LABA FDCs were not available for the majority of the study period, it should be noted that pathways to triple therapy use may change as the availability and use of FDCs grows. A UK database study showed that LAMA/LABA combination treatment (either free or fixed dose) was only used as a maintenance regimen in a small proportion (5\%) of patients [46]; however, its use will likely have increased considerably in the last 4 years, potentially impacting on treatment pathways. Additionally, changes in access to therapy or reimbursement levels were not analyzed.

\section{CONCLUSIONS}

In this retrospective cohort study conducted across the UK, Germany, Italy, France, and Australia, the three most common maintenance treatment pathways to triple therapy were ICS + LABA, no previous therapy, and LAMA only. Our results also demonstrated that a large number of different pathways could be observed both within and across countries. The differing impact of treatments may affect quality of life and disease control in patients with COPD. Future research is required to investigate the factors that influence pathways to triple therapy and disease outcomes related to these choices.

\section{ACKNOWLEDGEMENTS}

IQVIA Medical Research Data incorporates data from The Health Improvement Network, THIN. THIN is a registered trademark of Cegedim SA in the UK and other countries. Reference made to the THIN database is intended to be descriptive of the data asset licensed by IQVIA. This work uses de-identified data provided by patients as a part of their routine primary care. 
Funding. This study and the journal's Rapid Service Fee was supported by AstraZeneca. The funder of the study was involved in study design, data interpretation, and writing of the report.

Medical Writing Assistance. Medical writing support, under the direction of the authors, was provided by Karleen Nicholson, PhD, and Pauline Craig, PhD, CMC Connect, McCann Health Medical Communications, funded by AstraZeneca, Gaithersburg, USA in accordance with Good Publication Practice (GPP3) guidelines [47].

Authorship. All named authors meet the International Committee of Medical Journal Editors (ICJME) criteria for authorship for this article, take responsibility for the integrity of the work as a whole, and have given their approval for this version to be published.

Authorship Contributions. CO'L, AV, MM, $\mathrm{HR}$, and GB made substantial contributions to the acquisition and analysis of data. All authors made substantial contributions to the conception and design of the work, interpretation of the data, preparation and critical review of the manuscript, approved the final version to be submitted and agree to be accountable for all aspects of the work, in ensuring that questions related to the accuracy or integrity of any part of the work are appropriately investigated and resolved.

Disclosures. Jennifer K. Quint's research group has received funding from AstraZeneca, Bayer, Boehringer Ingelheim, British Lung Foundation, GlaxoSmithKline, Insmed, Medical Research Council, The Health Foundation and Wellcome Trust for other projects, none of which relate to this work. Jennifer K. Quint's research group has received funds from IQVIA relating to this work. Jennifer K. Quint has received funds from AstraZeneca, Bayer, Boehringer Ingelheim, Chiesi, GlaxoSmithKline and Teva for advisory board participation or travel. Caroline O'Leary, Alessandra Venerus, Melissa Myland, Hartmut Richter and Geoffray Bizouard are employees of IQVIA who received consulting fees for conducting the study.
Ulf Holmgren and Precil Varghese are employees of AstraZeneca. Claudia Cabrera is an employee of AstraZeneca and has an adjunct research position at the Karolinska Institute of Biostatistics and Epidemiology.

Compliance with Ethics Guidelines. Access to CPRD data was approved (16_298R) for this study by an Independent Scientific Advisory Committee (ISAC). ISAC is a non-statutory expert advisory body established in 2006 by the Secretary of State for Health to provide scientific advice on research requests to access data provided by CPRD. The THIN data collection was approved by the NHS South-East Multi-centre Research Ethics Committee (MREC) in 2003. Under the terms of this ethics approval, studies using pre-collected, pseudonymized data must undergo scientific review to help ensure appropriate analysis and interpretation of the data. The independent Scientific Review Committee (SRC), which was set up in July 2009, provided approval for the use of the THIN data for the current study (16THIN097). Approval was not required for the DA or LPD databases.

Data Availability. The data sets used and analyzed during the current study will be available on reasonable request in accordance with AstraZeneca's data sharing policy described at https://www.astrazenecagrouptrials. pharmacm.com/ST/ Submission/Disclosure

Open Access. This article is licensed under a Creative Commons Attribution-NonCommercial 4.0 International License, which permits any non-commercial use, sharing, adaptation, distribution and reproduction in any medium or format, as long as you give appropriate credit to the original author(s) and the source, provide a link to the Creative Commons licence, and indicate if changes were made. The images or other third party material in this article are included in the article's Creative Commons licence, unless indicated otherwise in a credit line to the material. If material is not included in the article's Creative Commons licence and your intended use is not permitted by statutory regulation or exceeds the permitted use, you will need to obtain permission directly from the 
copyright holder. To view a copy of this licence, visit http://creativecommons.org/licenses/by$\mathrm{nc} / 4.0 /$.

\section{REFERENCES}

1. World Health Organization. global health estimates 2016: deaths by cause, age, sex, by country and by region 2000-2016. 2018. https://www.who.Int/ healthinfo/global_burden_disease/estimates/en/. Accessed 11 April 2019.

2. World Health Organization. Chronic obstructive pulmonary disease (COPD) fact sheet. 2017. https:// www.who.int/news-room/fact-sheets/detail/ chronic-obstructive-pulmonary-disease(COPD). Accessed 21 Dec 2017.

3. Horst C, Ruparel M, Quaife S, et al. S130 the prevalence of undiagnosed COPD on spirometry and emphysema on low-dose CT scans in a lung cancer screening demonstration pilot: a teachable moment? Thorax. 2016;71(Suppl 3):S130.

4. Global Initiative For Chronic Obstructive Lung Disease. 2020 report: global strategy for the diagnosis, management and prevention of COPD. 2020. https://www.goldCOPD.org/gold-reports/. Accessed 17 Mar 2020.

5. Mannino DM, Higuchi K, Yu T-C, et al. Economic burden of COPD in the presence of comorbidities. Chest. 2015;148:138-50.

6. Kauppi P, Kupiainen H, Lindqvist A, et al. Overlap syndrome of asthma and COPD predicts low quality of life. J Asthma. 2011;48:279-85.

7. Rhee CK, Yoon HK, Yoo KH, et al. Medical utilization and cost in patients with overlap syndrome of chronic obstructive pulmonary disease and asthma. COPD. 2014;11:163-70.

8. Shaya FT, Dongyi D, Akazawa MO, et al. Burden of concomitant asthma and COPD in a Medicaid population. Chest. 2008;134:14-19.

9. Gibson PG, McDonald VM. Asthma-COPD overlap 2015: now we are six. Thorax. 2015;70:683-91.

10. Pauwels RA, Buist AS, Calverley PM, Jenkins CR, Hurd SS, GOLD Scientific Committee. Global strategy for the diagnosis, management, and prevention of chronic obstructive pulmonary disease. NHLBI/ Who Global Initiative For Chronic Obstructive Lung Disease (GOLD) workshop summary. Am J Respir Crit Care Med. 2001;163:1256-76.
11. Rodriguez-Roisin R, Rabe KF, Vestbo J, Vogelmeier C, Agusti A. Global Initiative For Chronic Obstructive Lung Disease (GOLD) 20th anniversary: a brief history of time. Eur Respir J. 2017;50:1700671.

12. Rabe KF, Hurd S, Anzueto A, et al. Global strategy for the diagnosis, management, and prevention of chronic obstructive pulmonary disease: GOLD executive summary. Am J Respir Crit Care Med. 2007;176:532-55.

13. Global Initiative For Chronic Obstructive Lung Disease. 2011 Report: global strategy for the diagnosis, management and prevention of COPD. 2011. https://www.goldCOPD.org/archived-reports/. Accessed 28 June 2019.

14. Global Initiative For Chronic Obstructive Lung Disease. 2015 Report: global strategy for the diagnosis, management and prevention of COPD. 2015. https://www.goldCOPD.org/archived-reports/. Accessed 4 Jan 2015.

15. Lipson DA, Barnhart F, Brealey N, et al. Once-daily single-inhaler triple versus dual therapy in patients with COPD. N Engl J Med. 2018;378:1671-80.

16. Papi A, Vestbo J, Fabbri L, et al. Extrafine inhaled triple therapy versus dual bronchodilator therapy in chronic obstructive pulmonary disease (TRIBUTE): a double-blind, parallel group, randomised controlled trial. Lancet. 2018;391:1076-84.

17. Ferguson GT, Rabe KF, Martinez FJ, et al. Triple therapy with budesonide/glycopyrrolate/formoterol fumarate with co-suspension delivery technology versus dual therapies in chronic obstructive pulmonary disease (KRONOS): a double-blind, parallel-group, multicentre, phase 3 randomised controlled trial. Lancet Respir Med. 2018;6:747-58.

18. Brusselle G, Price D, Gruffydd-Jones K, et al. The inevitable drift to triple therapy in COPD: an analysis of prescribing pathways in the UK. Int J Chron Obstruct Pulmon Dis. 2015;10:2207-17.

19. Di Marco F, Santus P, Terraneo S, et al. Characteristics of newly diagnosed COPD patients treated with triple inhaled therapy by general practitioners: a real world Italian study. NPJ Prim Care Respir Med. 2017;27:51.

20. Wurst KE, Punekar YS, Shukla A. Treatment evolution after COPD diagnosis in the UK primary care setting. PLoS ONE. 2014;9:E105296.

21. Meeraus W, Wood R, Jakubanis R, et al. COPD treatment pathways In France: a retrospective analysis of electronic medical record data from general practitioners. Int J Chron Obstruct Pulmon Dis. 2018;14:51-63. 
22. Lopez-Campos JL, Carrasco Hernández L, Muñoz X, Bustamante V, Barreiro E. Current controversies in the stepping up and stepping down of inhaled therapies for COPD at the patient level. Respirology. 2018;23:818-27.

23. Quint JK, Müllerová H, DiSantostefano RL, et al. Validation of chronic obstructive pulmonary disease recording in the Clinical Practice Research Datalink (CPRD-GOLD). BMJ Open. 2014;4: E005540.

24. Blak BT, Thompson M, Dattani H, Bourke A. Generalisability of the health improvement network (THIN) database: demographics, chronic disease prevalence and mortality rates. Inform Prim Care. 2011;19:251-5.

25. Herrett E, Gallagher AM, Bhaskaran K, et al. Data resource profile: Clinical Practice Research Datalink (CPRD). Int J Epidemiol. 2015;44:827-36.

26. National Health Service Digital. Hospital Episode Statistics Data Dictionary. 2018. https://www. digital.nhs.uk/data-and-information/data-toolsand-services/data-services/hospital-episodestatistics/hospital-episode-statistics-datadictionary. Accessed 20 Aug 2019.

27. Rothnie KJ, Müllerová H, Hurst JR, et al. Validation of the recording of acute exacerbations of COPD In UK primary care electronic healthcare records. PLoS ONE. 2016;11:E0151357.

28. Becher H, Kostev K, Schröder-Bernhardi D. Validity and representativeness of the "Disease Analyzer" patient database for use in pharmacoepidemiological and pharmacoeconomic studies. Int J Clin Pharmacol Ther. 2009;47:617-26.

29. Jouaville SL, Miotti H, Coffin G, Sarfati B, Meihoc A. PRM49 validity and limitations of the longitudinal patient database France for use in pharmacoepidemiological and pharmacoeconomics studies. Value Health. 2015;18:PRM49.

30. Lewis JD, Schinnar R, Bilker WB, Wang X, Strom BL. Validation studies of the health improvement network (THIN) database for pharmacoepidemiology research. Pharmacoepidemiol Drug Saf. 2007;16: 393-401.

31. Cavaillès A, Brinchault-Rabin G, Dixmier A, et al. Comorbidities of COPD. Eur Respir Rev. 2013;22: 454-75.

32. Müllerová H, Agusti A, Erqou S, Mapel DW. Cardiovascular comorbidity in COPD: systematic literature review. Chest. 2013;144:1163-78.
33. Lee AL, Goldstein RS. Gastroesophageal reflux disease in COPD: links and risks. Int J Chron Obstruct Pulmon Dis. 2015;10:1935-49.

34. Miller JJ. The inverse of the Freeman-Tukey double arcsine transformation. Am Stat. 1978;32:138.

35. Peterson AM, Nau DP, Cramer JA, Benner J, Gwadry-Sridhar F, Nichol M. A checklist for medication compliance and persistence studies using retrospective databases. Value Health. 2007;10:3-12.

36. Global Initiative For Chronic Obstructive Lung Disease. 2019 Report: Global Strategy for the Diagnosis, Management and Prevention of COPD. 2019. https://www.goldCOPD.org/archived-reports/. Accessed 28 Oct 2019.

37. Sehl J, O'Doherty J, O'Connor R, O'Sullivan B, $\mathrm{O}^{\prime}$ Regan A. Adherence to COPD management guidelines in general practice? A review of the literature. Ir J Med Sci. 2018;187:403-7.

38. Miravitlles M, Vogelmeier C, Roche $\mathrm{N}$, et al. A review of national guidelines for management of COPD in Europe. Eur Respir J. 2016;47:625-37.

39. Bargiel A, Obojski A. Impact of the GOLD 2011 guidelines on treatment regimen in COPD patients. Eur Respir J. 2015;46(Suppl. 59):PA3939.

40. Surani S, Aiyer A, Eikermann S, et al. Adoption and adherence to chronic obstructive pulmonary disease GOLD guidelines in a primary care setting. SAGE Open Med. 2019;7:2050312119842221.

41. Di Marco F, Verga M, Reggente M, et al. Anxiety and depression in COPD patients: the roles of gender and disease severity. Respir Med. 2006;100: 1767-74.

42. Nissen F, Morales DR, Müllerová H, Smeeth L, Douglas IJ, Quint JK. Concomitant diagnosis of asthma and COPD: a quantitative study in UK primary care. Br J Gen Pract. 2018;68:E775-82.

43. Chalmers JD, Laska IF, Franssen FME, et al. Withdrawal of inhaled corticosteroids in COPD: a European Respiratory Society guideline. Eur Respir J. 2020;55:2000351.

44. Watz H, Tetzlaff K, Wouters EFM, et al. Blood eosinophil count and exacerbations in severe chronic obstructive pulmonary disease after withdrawal of inhaled corticosteroids: a post-hoc analysis of the WISDOM trial. Lancet Respir Med. 2016;4:390-8.

45. Sharma N, Singh B, Siddiqui M, et al. Global treatment guidelines and patterns in COPD: focus on triple therapy. Poster P264 presented at: British Thoracic Society, 2019. 
46. Bloom CL, Elkin SL, Quint JK. Changes in COPD inhaler prescriptions in the United Kingdom, 2000 to 2016. Int J Chron Obstruct Pulmon Dis. 2019;14: 279-87.
47. Battisti WP, Wager E, Baltzer L, et al. Good publication practice for communicating company-sponsored medical research: GPP3. Ann Intern Med. 2015;163:461-4. 